\title{
Outcomes of Online Adaptation of the Universal Newborn Hearing Screening Certification
}

\author{
Carlos Diego A. Rozul, MClinAud,,1,2,3 Talitha Karisse L. Yarza, MClinAud ${ }^{2,3}$ \\ and Jaymilyn V. Catangay-Ombao, MClinAud $2,3,4$ \\ ${ }^{1}$ Research Implementation and Development Office, College of Medicine, University of the Philippines Manila \\ ${ }^{2}$ Newborn Hearing Screening Reference Center, National Institutes of Health, University of the Philippines Manila \\ ${ }^{3}$ Philippine National Ear Institute, National Institutes of Health, University of the Philippines Manila \\ ${ }^{4}$ Department of Speech Pathology, College of Allied Medical Professions, University of the Philippines Manila
}

\begin{abstract}
Objective. An adaptation of the newborn hearing screening personnel certification course to an online platform started development in June 2020. It was then implemented in July 2020. The current study aimed to evaluate the initial implementation of the online adaptation of the universal newborn hearing screening certification course among participants.
\end{abstract}

Methods. Through a concurrent mixed-methods research design, the study triangulated program outcomes, course evaluation, and key informant interviews of participants from July to November 2020 to evaluate the initial implementation of the course.

Results. The certification course participants had an overall positive experience with the initial implementation of the online adaptation. Only a minority of participants expressed their dissatisfaction with the course evaluation form. Moreover, the key informant interviews showed more detailed areas of improvement.

Conclusion. Despite the course's high ratings and administrative strengths, the use and features of Canvas as a learning management system were needed for participants to maximize the course. Furthermore, improvements in the presentation of the lectures and increasing the interactivity and engagement of the learning materials were recommendations in the refinement of the online course.

Keywords: newborn hearing screening, online learning, program implementation, learning management system

\section{INTRODUCTION}

In response to the COVID-19 pandemic and the continuing demand for newborn hearing screening personnel, the Newborn Hearing Screening Reference Center decided to adapt its certification course for these personnel on May 30, 2020. Utilizing the online platform Canvas (https://canvas.instructure.com/), learning modules were adapted into asynchronous multimedia learning materials programmed in the online learning management system.

The adapted certification course was first implemented on July 1, 2020, and has been continuously evaluated from an instructor's perspective. It is a self-paced asynchronous learning experience. Each course run lasts for a maximum

Corresponding author: Carlos Diego A. Rozul, MClinAud Philippine National Ear Institute National Institutes of Health

University of the Philippines Manila

Taft Avenue, Manila 1000, Philippines

Email: carozul@up.edu.ph of one month with two to three hours of content. Since its first implementation, the adapted course has been run a total of six times. Changes and revisions from the previous face-to-face implementation have been described by Rozul, Yarza, Catangay-Ombao, and Cruz. ${ }^{1}$ 
In collaboration with 70 hospitals and 10 Early Hearing Detection \& Intervention Centers, Utah State University formulated a 70-minute newborn hearing screening course containing eight sections (two of which are optional) and a competency checklist for program managers. ${ }^{2}$ Initially designed to be distributed through DVD, the course can now be accessed for free online. By registering in a learning management system, participants can receive a certificate of completion for the course. Jones, Lambert, and Barnett found that knowledge about newborn hearing screening increased immediately after the training program. ${ }^{3}$

There are situations wherein online learning may be dissatisfying such as those involving complex psychomotor skills. ${ }^{4}$ In these situations, it is more favorable to utilize blended learning. ${ }^{5}$ Nonetheless, in-person and web-based training delivery are comparable for participation, satisfaction, and knowledge acquisition outcomes. Furthermore, webbased learning was seen to be more efficient, but participants perceive in-person learning to be more cost-effective. ${ }^{6}$ The current study aimed to evaluate the initial implementation of the online adaptation of the universal newborn hearing screening certification course among participants.

\section{MATERIALS AND METHODS}

\section{Study Design}

A concurrent mixed-methods research design was utilized to describe and evaluate the adaptation of the universal newborn hearing screening certification course to Canvas. Quantitative and qualitative data were used in conjunction with each other to meet study objectives.

\section{Participants}

Potentially, all participants enrolled in the certification course from July to November 2020 were included in the research. Participation included a collection of aggregate course evaluation data and key informant interviews (KII). The participants are first-time applicants of the newborn hearing screening personnel certification course.

\section{Data Collection}

This study utilized multiple data sources to increase validity and decrease the bias of the research findings. Informed consent was collected upon participants' registration to the course and once more prior participation in the KII. Inquiries regarding the use of data were answered and did not impact their eligibility to pursue the certification course. Furthermore, findings from the interview did not influence participants' performance outcomes in the course. The following methods were used to collect the data from each source.

\section{Outcomes from Program Database}

Program outcomes from the certification course secretariat were utilized. Aggregate data from July to
November 2020, including (1) dropout rate, (2) passing rate, and (3) retake rate, was collected.

Participants were required to pass both the written and practical examinations to become certified newborn hearing screeners. They were initially evaluated with a written test, which was a prerequisite for the practical examination. Participants who did not meet the passing score of the written examination component were given a chance to retake the course in the subsequent month but were considered as failed in the initial month's outcomes. The same was applied to participants who did not pass the practical examination. A more detailed description of the evaluation process was described by Rozul, Yarza, Catangay-Ombao, and Cruz. ${ }^{1}$

\section{Course Evaluation}

An evaluation tool utilized by the Newborn Hearing Screening Reference Center was adopted to assess the acceptability of changes made in the online certification course. The evaluation tool used a five-point Likert scale assessing the following areas: (1) course design, (2) course rationale and objectives, (3) navigation of platform, (4) module content and delivery, and (5) evaluation of performance assessment. The tool also utilized a checklist of learning satisfaction and an optional open-ended questionnaire about how the course can be improved. Evaluation from October to November implementations was included.

\section{Focus Group Discussion among Program Faculty regarding Implementation}

Program faculty of the certification course met every month after a course run to discuss outcomes and problems encountered during the implementation. Possible solutions and mediations to problems discussed were determined through the focus group discussions.

\section{Key Informant Interviews}

Semi-structured interviews were conducted to collect insights among July to November participants regarding their experiences while going through the online course. The interviews were done over a secure online conferencing application. These were recorded and stored in a limited access cloud storage system. The investigators developed a topic guide. The interviews gave further evidence on the collected programs outcomes and course evaluation results.

\section{Data Analysis}

Due to the nature of the mixed-methods design used, the study aimed to triangulate the results through data and methodological triangulation. Multiple data sources were utilized to triangulate results towards describing and evaluating the online adaptation of the universal newborn hearing screening personnel certification course.

Descriptive statistics and measures of central tendency were used as a statistical treatment for course evaluation forms. Key informant interviews were transcribed while 
taking note of nonverbal cues that contextualized responses. A thematic analysis was done to synthesize findings from the interviews. Findings were coded according to (1) facilitating factors, (2) barriers, and (3) burdens.

\section{RESULTS AND DISCUSSION}

There were a total of 156 participants who enrolled in the certification course from July to November 2020. Among them, 153 (98.08\%) completed the course on time, while three (1.92\%) were counted as dropouts as they did not access the teaching materials nor take the written and practical examinations. A total of $128(82.05 \%)$ participants passed the course during their first try. Three $(12.00 \%)$ of the 25 individuals who failed decided to retake the exam in the subsequent months. Table 1 shows the outcomes of the participants according to month.

There was a significant increase in participants who failed (44.83\%) in the October 2020 course. This may be attributed to implementing a revised rubric that increased the passing score from 12 out of 17 to 16.5 out of 17 . The change was made due to examiners experiencing varied competency levels among examinees. Participants could only pass without showing mastery of key concepts, especially when it came to the stop criteria and patient counseling.

The implementation of the online adaptation of the newborn hearing screening certification course yielded a high completion rate. Beyond the course being a requirement to be a certified newborn hearing screening personnel, the course also shared qualities of online courses with high completion rates. These included relatively short course length and automated written examination grading. ${ }^{7}$

\section{Course Evaluation}

The adapted course evaluation form was implemented starting October 2020. There were 57 enrollees from October to November 2020 who answered the evaluation tool. On average, the participants rated the course 4.4 and higher across all aspects. The highest-rated lecture was Lecture 4: Records and Reports (4.62), while the lowest-rated was Lecture 1: Introduction to RA 9709 (4.41). Table 2 shows the average ratings of participants.

Most participants' positive comments supported the high ratings, citing the asynchronous nature of the course beneficial for a self-paced learning program. Furthermore,

Table 1. Participant Outcomes per Month $(n=156)$

\begin{tabular}{lcccc}
\multicolumn{1}{c}{ Month } & Enrolled & Passed & Failed & Dropouts \\
July 2020 & 18 & 18 & 0 & 0 \\
\hline August 2020 & 53 & 49 & 4 & 0 \\
\hline September 2020 & 28 & 26 & 2 & 0 \\
\hline October 2020 & 29 & 15 & 13 & 1 \\
\hline November 2020 & 28 & 20 & 6 & 2 \\
\hline
\end{tabular}

the inclusion of COVID-19 protocols across relevant lectures was seen as a strength of the course among participants.

Despite the relatively high ratings, a minority of participants expressed dissatisfaction with certain areas of the course. One of which was difficulty in initially accessing the learning materials due to poor internet connection. The absence of synchronous options, methods of interactive discussion, or both was cited as a weakness by the participants. Furthermore, a minority of participants expressed difficulty in complying with the video-recording option for the practical examination.

\section{Problems encountered in evaluation meetings}

After every course, evaluation meetings were held to review program highlights, processes, logistics, outcomes, and issues encountered. The results of these meetings provided a basis for modification and adjustments of the different aspects of the program. From the perspective of the implementers, a few of the main concerns that were not covered in the course evaluation form was compliance with deadlines and ensuring standardized scoring by the examiners for the practical examination.

The non-compliance of participants to the set deadlines was addressed by clarifying the program rules and guidelines in the communication letters distributed and additional instruction in navigating the platform, accessing the modules, and completing the requirements. ${ }^{8,9}$

For the practical examination, a checklist used for the face-to-face practical examination was adapted for online implementation. As it is skill-based and scored by different examiners, assigning points may vary. ${ }^{10}$ Participants may also interpret and demonstrate the required skills differently. This warranted the revision of the checklist to a structured rubric defining specific criteria for scoring, which is made available to both the participants and examiners. ${ }^{11}$ This was implemented on the October 2020 course.

\section{Key Informant Interviews}

Only eight of the 156 participants from July to November 2020 consented to participate in the KII. Similarly, to the course evaluation, the KII revealed that participants had a positive impression of their experience in the certification course. However, the following themes have been expressed. Table 3 summarizes the demographics of the participants of the KII.

\section{Facilitating Factors}

Participants expressed that they had positive experiences with the administrative management of the online certification course. Submission of the requirements was straightforward and efficient. When it came to the price of the course, the majority of the participants said that the price point was worth the content and delivery of the certification course. A price increase was perceived to be acceptable with proper justification citing enhancement of 
platform, materials, and the permanency of the online course. The majority of the participants also appreciated how the modules could be accomplished in a self-paced manner due to their increased workload during the COVID-19 pandemic.

\section{Barriers}

It's hard because you don't know where to start, what are you going to do. - Participant NHSA03

Table 2. Course Evaluation $(n=57)$

\begin{tabular}{|c|c|}
\hline Course Aspect & $\begin{array}{c}\text { Average } \\
\text { Rating }\end{array}$ \\
\hline \multicolumn{2}{|l|}{ A. Course Design } \\
\hline Program content met my needs. & 4.75 \\
\hline Length of the course was adequate. & 4.70 \\
\hline \multicolumn{2}{|l|}{ B. Course Rationale and Objectives } \\
\hline I understood the different aspects of RA 9709. & 4.72 \\
\hline I gained knowledge and skills on OAE and AABR. & 4.73 \\
\hline I am confident to report results. & 4.75 \\
\hline I can facilitate forms and PhilHealth claims. & 4.74 \\
\hline \multicolumn{2}{|l|}{ C. Navigation of Platform } \\
\hline It was easy to use the online platform. & 4.50 \\
\hline It was easy to communicate with the admin. & 4.64 \\
\hline It was easy to communicate with the examiner. & 4.58 \\
\hline The platform used was helpful as a student. & 4.64 \\
\hline \multicolumn{2}{|l|}{ Lecture 1: Introduction to RA 9709} \\
\hline Content was presented in an organized manner. & 4.46 \\
\hline Content was presented clearly and effectively. & 4.43 \\
\hline Teaching aids/visuals were used effectively. & 4.41 \\
\hline Teaching style was effective. & 4.35 \\
\hline Content met stated objectives. & 4.40 \\
\hline Content was applicable to my practice. & 4.41 \\
\hline Language used was simple and understandable. & 4.43 \\
\hline \multicolumn{2}{|c|}{ Lecture 2: Newborn Hearing Screening and Hearing Tests in Infants } \\
\hline Content was presented in an organized manner. & 4.56 \\
\hline Content was presented clearly and effectively. & 4.58 \\
\hline Teaching aids/visuals were used effectively. & 4.55 \\
\hline Teaching style was effective. & 4.52 \\
\hline Content met stated objectives. & 4.58 \\
\hline Content was applicable to my practice. & 4.59 \\
\hline Language used was simple and understandable. & 4.58 \\
\hline \multicolumn{2}{|l|}{ Lecture 3: Intervention for Infants with Hearing Loss } \\
\hline Content was presented in an organized manner. & 4.48 \\
\hline Content was presented clearly and effectively. & 4.45 \\
\hline Teaching aids/visuals were used effectively. & 4.47 \\
\hline Teaching style was effective. & 4.48 \\
\hline Content met stated objectives. & 4.47 \\
\hline Content was applicable to my practice. & 4.45 \\
\hline Language used was simple and understandable. & 4.42 \\
\hline
\end{tabular}

The majority of the KII participants did not have prior experience with online learning. Half of the participants shared that they experienced initial difficulty navigating Canvas but could engage in the learning material after gaining familiarity with the platform. Despite this, however, only a minority discovered the full features of the Canvas platform, such as downloading learning materials. These concerns were similar to those expressed by medical students in a study by Baticulon. ${ }^{9}$

\begin{tabular}{lc}
\multicolumn{1}{c}{ Course Aspect } & $\begin{array}{c}\text { Average } \\
\text { Rating }\end{array}$ \\
\hline Lecture 4: Records and Reports & \\
Content was presented in an organized manner. & 4.59 \\
Content was presented clearly and effectively. & 4.59 \\
Teaching aids/visuals were used effectively. & 4.58 \\
Teaching style was effective. & 4.61 \\
Content met stated objectives. & 4.63 \\
Content was applicable to my practice. & 4.61 \\
Language used was simple and understandable. & 4.63 \\
\hline Lecture 5: PhilHealth and Updates & \\
Content was presented in an organized manner. & 4.59 \\
Content was presented clearly and effectively. & 4.59 \\
Teaching aids/visuals were used effectively. & 4.56 \\
Teaching style was effective. & 4.58 \\
Content met stated objectives. & 4.61 \\
Content was applicable to my practice. & 4.59 \\
Language used was simple and understandable. & 4.59 \\
\hline Lecture 6: Local Experience & \\
Content was presented in an organized manner. & 4.53 \\
Content was presented clearly and effectively. & 4.52 \\
Teaching aids/visuals were used effectively. & 4.48 \\
Content met stated objectives. & 4.53 \\
Content was applicable to my practice. & 4.55 \\
\hline D. Evaluation of Performance & 4.31 \\
\hline
\end{tabular}


Table 3. Demographics of Key Informant Interviews $(\mathrm{N}=8)$

\begin{tabular}{lc}
\multicolumn{2}{c}{ Demographic } \\
\hline Age (years) & $26-44$ \\
\hline Sex & 3 \\
Male & 5 \\
Female & \\
\hline Occupation & 1 \\
Physician & 3 \\
Nurse & 1 \\
Midwife & 2 \\
Clinician & 1 \\
Audiologist & \\
\hline Outcome & 4 \\
Passed both exams in 1st take & 3 \\
Retake in written & 1 \\
Retake in practical & \\
\hline Experience with online & 5 \\
First time & 3 \\
Previous experience &
\end{tabular}

A minority of participants also shared how references to the course were not organized about how it related to the modules. Thus, some participants could not access supplementary materials such as the manual of operations of RA9709. This concern was similar to the results of the comments made in the course evaluation.

\section{Burdens}

More than half of the participants shared their preference with face-to-face and synchronous learning sessions; however, they deemed the online learning experience necessary given the COVID-19 pandemic.

I like online training if it's going to be like, uhb, in the context of, uhh, with the theories, book-based type, but if it's going to be a discussion type, I would prefer to have it face-to-face. - Participant NHSA02

However, a recurrent suggestion among the participants was enhancing the presentations with more lively and interactive learning activities. This was an essential component in maximizing the benefit of videos in online learning programs. ${ }^{12}$ The opportunity to directly ask questions and create discussions was a feature that participants felt could improve the course. Additionally, participants expressed the benefit of interactive post-module activities before written and practical examinations to increase confidence. They also suggested including demonstrations of the processes involved as newborn hearing screening personnel. These sentiments were also expressed in the course evaluation. However, in a study by Hendriks et al., less than $15 \%$ of online courses provided collaboration and real-time expert feedback opportunities. ${ }^{13}$
A minority of participants perceived portions of the course material, particularly in the third and fourth lectures, to be too technical for participants without a health science background. This echoes the need to consider agile pedagogy of the course content and design to accommodate the variations of learners who participated in the certification course. $^{14}$

The majority of participants preferred to submit videos for the evaluation as compared to synchronous online conferencing sessions. However, some participants found it challenging to execute the video as it required the help of a colleague to shoot the video. Synchronous sessions had low adaptation, with poor internet connection being a concern among participants.

\section{CONCLUSION}

The current study aimed to evaluate the online implementation of the certification course for newborn hearing screening personnel. Overall, the participants were satisfied with the conduct of the online certification course. Most notably, its strength was in its administrative processes of registration and provision of certificates. Furthermore, its self-paced nature was cited as a benefit as participants experienced increased workload during the COVID-19 pandemic. Participants also expressed that they were evaluated relatively fairly. Overall, most participants said that the course content was complete. However, they missed the interactivity present in a face-to-face setting, such as live discussions and lively delivery of lectures.

It is recommended that future iterations of the certification course address the concerns expressed by the participants, most especially increasing the engagement of the course. These can be done through revisions in the delivery of the course content and the creation of demonstrative videos on the use of screening devices, counseling, and registry cards. Furthermore, it is beneficial to provide participants with an avenue to raise concerns and questions regarding topics discussed in the course and integrate opportunities for formative assessment in between lectures.

\section{Acknowledgments}

The research team would like to acknowledge its research assistant Maria Isabella Katerina M. Lacson, MClinAud, and its administrative aide Lyneth V. Fria for the assistance in organizing and collecting the data.

\section{Statement of Authorship}

All authors participated in data collection and analysis and approved the final version submitted.

\section{Author Disclosure}

All authors declared no conflicts of interest. 


\section{Funding Source}

This study was funded by the Newborn Hearing Screening Reference Center.

\section{REFERENCES}

1. Rozul CDA, Yarza TKL, Catangay-Ombao JV, Cruz TLG. Development and Pilot Implementation of the Online Certification of Universal Newborn Hearing Screening Personnel. Acta Med Philipp. 2021 June. DOI: https://doi.org/10.47895/amp.vi0.3361.

2. Winston R. Introducing the Newborn Hearing Screening Training Curriculum. Perspect Hear Hear Disord Child. 2008 Oct;18(2):39-43.

3. Jones AL, Lambert AW, Barnett M. Nursing Students: Training and Maintaining Universal Newborn Hearing Screening Knowledge. Nurse Educ Pract. 2018 Sep 1;32:72-7.

4. Kastl G, Koeffler NM. The Assistant Doctors' Experience and Vocational Training Satisfaction in Ophthalmology in Bavaria: Outcomes of an Online Survey with Evaluation of the Vocational Training in Ophthalmic Surgery. Klin Monbl Augenheilkd. 2018 Apr 11;235(12):1398-406

5. Yousef AM, Chatti MA, Schroeder U, Wosnitza M. A Usability Evaluation of a Blended MOOC Environment: An Experimental Case Study. Int Rev Res Open Dis. 2015;16(2):69-93.

6. Maloney S, Haas R, Keating JL, Molloy E, Jolly B, Sims J, et al. Breakeven, Cost Benefit, Cost Effectiveness, and Willingness to Pay for Web-based versus Face-to-face Education Delivery for Health Professionals. J Med Internet Res. 2012;14(2):e47.
7. Jordan K. Massive Open Online Course Completion Rates Revisited: Assessment, Length and Attrition. Int Rev Res Open Dis. 2015;16(3):341-58.

8. Cleland J, Chu J, Lim S, Low J, Low-Beer N, Kwek T. COVID 19: Designing and Conducting an Online Mini-multiple Interview (MMI) in a Dynamic Landscape. Med Teach. 2020; 42(7): 776-780. DOI: 10.1080/0142159X.2020.1762851.

9. Baticulon RE, Sy JJ, Alberto NR, Baron MB, Mabulay RE, Rizada LG, et al. Barriers to Online Learning in the Time of COVID-19: A National Survey of Medical Students in the Philippines. Med Sci Educ. 2021:1-12.

10. McKenna S. Assessment Rubric as a Means of Making Academic Expectations Explicit. J. Indept Teach Learn. 2007;2:22-30.

11. Allen D, Tanner K. Rubrics: Tools for Making Learning Goals and Evaluation Criteria Explicit for Both Teachers and Learners. CBE Life Sc Educ. 2006;5(3):197-203. doi:10.1187/cbe.06-06-0168.

12. Brame CJ. Effective Educational Videos: Principles and Guidelines for Maximizing Student Learning from Video Content. CBE Life Sc Educ. 2016 Dec;15(4):es6.

13. Hendriks RA, de Jong PG, Admiraal WF, Reinders ME. Instructional Design Quality in Medical Massive Open Online Courses for Integration into Campus Education. Med Teach. 2020 Feb 1;42(2):156-63.

14. Supriyatno T, Kurniawan F. A New Pedagogy and Online Learning System on Pandemic COVID 19 Era at Islamic Higher Education. ICET. 2020. Oct 17 (pp. 7-10). IEEE. 